\title{
Effect of Subtotal Colectomy on Body Weight and Food Intake in an Experimental Model of Obesity in Male Wistar Rats
}

\author{
Pilar Fernández-Mateos ${ }^{1}$, Judith Ríos-Lugo ${ }^{2}$, Pilar Cano-Barquilla², Vanesa Jiménez-Ortega ${ }^{2}$, Ana I. \\ Esquifino $^{2, *}$ and Alvaro Larrad ${ }^{3}$
}

${ }^{I}$ Departamento de Biología Celular, Facultad de Medicina, ${ }^{2}$ Departamento de Bioquímica y Biología Molecular III, Universidad Complutense Madrid, Spain

${ }^{3}$ Unidad Médico-Quirúrgica de Endocrinología, Hospital Nuestra Sra. del Rosario, Madrid, Spain

\begin{abstract}
The present work analyses the possible influence of the colon in weight gain of obese animals. Subtotal colectomy was performed in rats fed with standard chow or high-fat diets. The results, suggested that subtotal colectomy did not exert any effect on the \% of weight gain in rats administered a high-fat diet during the whole experiment as compared to controls. Animals submitted to a high-fat diet during the pre-surgery period and to a standard diet during the post-surgery period gained a lesser $\%$ of weight gain as compared to control or high-fat fed rats, together with a decrease in this parameter in colectomized animals. These changes did not agree with average food intake in rats fed with standard or high-fat diets. Surprisingly, the increase in body weight of sham-operated or subtotal colectomized rats fed with highfat diet cannot be explained by a diminished food intake when compared to controls. Moreover, the change in food intake after surgery showed a correlation with body weight in sham-operated animals, although this correlation disappeared in colectomized rats. Mortality only appeared in colectomized rats administered a high-fat diet. However, stool was normalized and presented normal characteristics when animals returned to be fed with their respective diet after surgery. The results of this study support the concept that the maintenance of a high fat diet may originate a decrease of the intake, overall in subtotal colectomized rats, possibly through neuroendocrine mechanisms related to gut hormones or to adaptive mechanism along the gastrointestinal tract.
\end{abstract}

Keywords: Colon and obesity, subtotal colectomy and obesity, surgical models and obesity.

\section{INTRODUCTION}

The manipulation of the gastrointestinal tract has been widely studied in rats and in humans. [1]. Nowadays, some of these manipulations were recuperated for obesity treatment $[2,3]$.

In previous studies from the laboratory, a mal-absorption syndrome, induced by biliopancreatic diversion, was developed to treat obesity in both humans [4-6] and rodents [7, 8], obtaining better long-term results [4] than other treatments [9]. However, one third of the patients or rodents gained weight again showing similar results $[4,5,8]$. This undesirable effect may be due to a not well-defined gut adaptation mechanism, [5] in which the colon may be involved. In fact, this adaptive mechanism was suggested in previous works from the literature [10-12]. Moreover recent data directly implicated the colon in body weight gain, through changes in the number and bacterial strains present in this segment of the gut, thus modifying the carbohydrate absorption rate $[13,14]$ although other works did not show such effects [15].

Considering all the above mentioned data the aim of the present work was to analyse the effects of surgical resection

*Address correspondence to this author at the Departamento de Bioquimica y Biologia Molecular III, Facultad de Medicina, Universidad Complutense, 28040 Madrid, Spain; Tel: 34913947189; Fax: 34913941691 ;

E-mail: pelayos@med.ucm.es of the colon on body weight gain, stool quality and food intake in obese male rats.

\section{MATERIAL AND METHODS}

\section{Animals}

Adult male Wistar rats were used in this study. They were maintained under standard conditions with controlled light $(12: 12 \mathrm{~h} \mathrm{light/dark} \mathrm{schedule;} \mathrm{lights} \mathrm{on} \mathrm{at} \mathrm{08:00} \mathrm{h)} \mathrm{and}$ temperature $(22 \pm 2 \mathrm{C})$. The care and use as well as all procedures involving animals were approved by the Institutional Animal Care Committee, Complutense University, Madrid, Spain. The study was also done in accordance with the guidelines of the Institutional Care and Use Committee of the National Institute of Health and the Guide for the Care and Use of Laboratory Animals (Institute of Laboratory Animal Resources, 1996) [16].

Animals were divided into three groups:

GROUP A: 8 controls and 8 subtotal colectomized rats fed with a standard diet for the pre surgery and post surgery periods. Specifications of the diet can be seen in Table 1.

GROUP B: 7 control and 7 subtotal colectomized rats fed with a high fat diet during the pre and post surgery periods. Specifications of the diet can be seen in Table 1 .

GROUP C: 8 control and 8 subtotal colectomized rats fed with a high fat diet during the pre-surgery period followed 
Table 1. Diet Composition

\begin{tabular}{|c|c|c|}
\hline & Standard & High Fat Diet \\
\hline \hline Fat & $3 \%$ & $35 \%$ \\
\hline Carbohydrates & $60 \%$ & $35 \%$ \\
\hline Proteins & $16 \%$ & $20 \%$ \\
\hline Vitamins and Minerals & 21 & 10 \\
\hline Kcal/gr. & 2.9 & 5.4 \\
\hline
\end{tabular}

Table 2. Body Weight Changes (gr)

\begin{tabular}{|c|c|c|c|c|}
\hline & Pre-Surgery & 1st Week after & Final & $\%$ Weight-Gain \\
\hline \multicolumn{5}{|l|}{ GROUP A } \\
\hline Control & $434.4 \pm 40$ & $461.3 \pm 15.2$ & $543.2 \pm 13.8$ & $+23.2 \pm 3.6^{(1)}$ \\
\hline Operated & $465.1 \pm 7.6$ & $418.5 \pm 10.4$ & $564.15 \pm 9.4$ & $+17.4 \pm 1.8$ \\
\hline \multicolumn{5}{|l|}{ GROUP B } \\
\hline Control & $544.86 \pm 11$ & $533.7 \pm 6.4$ & $663.8 \pm 11.9$ & $+21.9 \pm 1.2^{(2)}$ \\
\hline Operated & $562.33 \pm 11.5$ & $504.7 \pm 8.5$ & $699.5 \pm 34.3$ & $+23.2 \pm 8.4$ \\
\hline \multicolumn{5}{|l|}{ GROUP C } \\
\hline Control & $469.1 \pm 13.4$ & $448.9 \pm 5.6$ & $495.10 \pm 6.5$ & $+5.5 \pm 1.3^{(3)}$ \\
\hline Operated & $501.4 \pm 13.4$ & $439.4 \pm 7.3$ & $472.15 \pm 10.9$ & $-5.6 \pm 2.3$ \\
\hline
\end{tabular}

by a standard diet from the post-surgery period to sacrifice. Specifications of the diets used can be seen in Table $\mathbf{1}$.

\section{Surgical Procedure}

The animals were individually caged and fasted for $24 \mathrm{~h}$ before surgery. Animals were anaesthetized with a mixture of 3 parts of halothane and 8 parts of oxygen to be inhaled. A medial laparotomy to reach the colon followed by a subtotal colectomy, were performed. The surgery comprises terminal ileum up to $1 \mathrm{~cm}$ to the ileocecal valve, ascending, transverse, and descending colon up to sigmoid colon leaving $3 \mathrm{~cm}$ of colon up to the rectum. Intestine continuity was performed through an end-end ileo sigmostomy using a $6 / 0$ silk inverting purse-string suture. After surgery animals remained isolated for another 4 days and fed with a $5 \%$ glucose solution in water plus antibiotics (Baytril, Pittsburgh, PA , USA; $25 \mathrm{mg} / \mathrm{kg}$ ) and meloxicam (Metacam Boehringer Ingelheim Ltd UK; $1 \mathrm{mg} / \mathrm{kg}$ ). From day $5 \mathrm{on}$, the animals were fed ad libitum with the corresponding diet according to the groups described above: high fat. (Harland Tekland D03307, 35\% Lard Diet, Barcelona Spain) or standard diet ( SAFE Panlab A04, Barcelona, Spain). Diet details are given in Table $\mathbf{1}$.

Animal were weighted and sacrificed through decapitation 14 weeks after surgery. Also, food intake, stool quality and spontaneous mortality were evaluated.

\section{Statistical Analysis}

Statistical analysis of the results was performed by a oneway analysis of variance (ANOVA) and a Student's t test, and $\mathrm{p}$ values lower than 0.05 were considered statistically significant.

\section{RESULTS}

In groups $\mathrm{A}$ and $\mathrm{C}$, mortality did not occur along the time of the experiment. However, in group B, 2 animals died on week 8 and 9 after surgery, weighting 480 and 515 grams respectively. Those animals did not show any previous apparent disease. In operated animals, diarrhoea followed up to 3 days after surgery and from this day-point on, the stool was gradually thicker and normal, independently of the ingested diet or group considered.

Body weights can be observed in Table 2. Initial body weight increased in those animals fed with the high fat diet as compared to the control group. Subtotal colectomy did not change the total percent increase of body weight in both standard-fed (A) and high fat-fed rats (B). However, rats presurgery submitted to a high fat diet and post-surgically administered a standard diet (C) exhibited a differential effect on body weight. Whereas in sham-operated rats a 5.6 \pm 1.3 percent increase in body weight was detected, colectomized animals displayed a $5.6 \pm 2.3$ percent decrease in body weight $(\mathrm{P}<0.003$ vs. initial body weight).

Changes in food intake modifications are shown in Table 3. Independently of the considered group, animals fed with a high fat diet tended to consume more food during the pre surgery period, as compared to rats fed with a standard rat chow. Animals of group A, consumed higher amounts of food during the post surgery period as compared to the pre surgery period $(\mathrm{P}<0.001)$. Moreover, the increase in food 
Table 3. Food Intake Measurements (Mean Weekly Value in gr.)

\begin{tabular}{|c|c|c|c|}
\hline & Before Surgery & After Surgery & $\%$ \\
\hline Control & $124.13 \pm 1.86^{(1)}$ & $163.63 \pm 5.65$ & +23.9 \\
\hline \multicolumn{4}{|l|}{ GROUP B } \\
\hline Control & $135.24 \pm 4.6^{(1)}$ & $106.40 \pm 1.94$ & -27.3 \\
\hline \multicolumn{4}{|l|}{ GROUP C } \\
\hline Control & $133.07 \pm 8.37^{(1)}$ & $139.53 \pm 3.89$ & +4.3 \\
\hline Operated & $130.35 \pm 4.67^{(1)}$ & $146.62 \pm 6^{(4)}$ & +10.9 \\
\hline
\end{tabular}

intake during the post surgery period in subtotal colectomized rats of this group was significantly higher $(\mathrm{P}<$ 0.004 ) as compared to sham-operated controls.

In rats of group $\mathrm{B}$, subtotal colostomy significantly reduced food intake $(\mathrm{P}<0.001)$ as compared to shamoperated control animals of the same group or from the A group $(\mathrm{P}<0.001)$. It is of interest to note that colectomized animals of group B ingested the lowest amount of food during the post surgery period as compared to any other group.

In rats of group $\mathrm{C}$, food intake was not significantly increased during the post surgery as compared to the pre surgery periods. However, these values were statistically significant when compared those in animals fed with a high fat diet (group B) during the post surgery period. Globally the change in diet intake after surgery in group $\mathrm{C}$, tended to increase food intake to that consumed by rats of the group A, fed with a standard diet.

Animals fed with a standard diet during all the experiment (group A) and animals fed with a standard diet only during the post surgery period (group C) ingested a higher amount of food $(\mathrm{P}<0.001)$. This effect was more evident in colectomized rats of group A $(\mathrm{P}<0.004)$.

\section{DISCUSSION}

The results of this study, suggested that subtotal colostomy did not exert any effect on the final \% of weight gain in rats administered a standard rat chow or a high fat diet during the whole experiment. Thus, control animals as much as subtotal colectomized ones of groups A and B increased their body weight as expected, although, the final weight of high fat fed rats were significantly higher than controls. On the other hand, animals submitted to a high fat diet during the pre surgery period (group C) and to a standard diet during the post surgery period showed a lesser $\%$ of weight gain as compared to rats from groups A and B. Moreover, a decrease in the \% of weight gain was observed in subtotal colectomized animals of group C. It is of interest to note that the increases in body weight seemed no to be dependent of the amount of calories ingested per gram of diet $(2,9 \mathrm{Kcal} / \mathrm{gr}$. for standard diets or $5,4 \mathrm{Kcal} / \mathrm{gr}$ - for high fat diets). These changes did not agree with the modifications in the amount of diet consumed per average in rats of the groups $\mathrm{B}$ and $\mathrm{C}$ as compared to control animals of group A.

In our knowledge this is the first report showing the effects of subtotal colectomy in obese rats (group B). It is of interest to note that there was a similar \% of weight gain in control animals of group B as compared to control rats of group A although the final weight was clearly higher in control animals fed with the high fat diet. A similar approach can be done for subtotal colectomized rats of both groups A and B. Surprisingly, the increase in body weight of shamoperated or subtotal colectomized animals of group B can not be explained by food intake as this parameter was clearly reduced when compared the consumption of group A either control or subtotal colectomized ones. Moreover, the change in the diet consumed by animals from group $\mathrm{C}$ indicate that there was a correlation between bodies weigh and food intake in control animals, although this correlation disappeared in subtotal colectomized rats of the same group.

As expected, the results obtained for the weight changes and food intake in subtotal colectomized animals of the A group confirmed previous works from the literature [15]. However, the data obtained in groups B and C may indicate that the high fat diet administered during the pre surgery period may be inducing changes in number and strains of colon bacteria $[17,18]$ thus modifying carbohydrate absorption in the this segment of gut. This is important as carbohydrate absorption through the colon might exert a major influence in the host energetic balance $[19,20]$. According with this mechanism, the maintenance of a high fat diet reduced the long-term food intake of control obese rats. This effect was more evident in rats of the same group subjected to subtotal colectomy, which drastically reduced the number of bacteria. However, this effect of food intake tended to normalize when the animals changed the consumed diet from high fat to standard rat chow. Another explanation may include adaptive mechanisms of the gastrointestinal tract in response to both the diet and the subtotal colectomy [15]. 
Although, fat is the group of food with a low satiating power [21] it may be possible that its high calorie content activate the proximal gut segments signals. These proximal signals could induce on the one hand, a rapid PYY secretion at the distal gut segment, but in parallel it may induce an activation of the distal gut segment signals due to the faster arrival of food to sigma and rectum, in which PYY is highly accumulated [22]. Also, it has to be considered a decrease of ghrelin secretion by overfeeding, as much as the high calorie content of food [23].

In summary, subtotal colectomy seems not to modify the ultimate body weight of the studied animals. The differences found on body weight depended on the diet ingested. The results of this study support the concept that the maintenance of a high fat diet may originate a decrease of the intake, overall in subtotal colectomized rats, possibly through neuroendocrine mechanisms related to gut hormones or to adaptive mechanism along the gastrointestinal tract.

\section{CONFLICT OF INTEREST}

The authors confirm that this article content has no conflicts of interest.

\section{ACKNOWLEDGEMENTS}

This work was supported by a Grant from the Mutua Madrileña Foundation (Madrid), Spain. J.R.L was supported by a postdoctoral fellowship from the Complutense University.

\section{REFERENCES}

[1] Mok HY, Perry PM , Dowling RH. The control of bile acid pool size: Effect of jejunal resection and phenobarbitone on bile acid metabolism in the rat. Gut 1974; 15: 247-53.

[2] Bult MJ, Van Dalen T, Muller AF. Surgical treatment of obesity. Eur J Endocrinol 2008; 158:135-45.

[3] Schroeder R, Garrison JM Jr, Johnson MS. Treatment of adult obesity with bariatric surgery.Am Fam Physician 2011; 84: 805-14.

[4] Larrad-Jiménez A. Larrad biliopancreatic diversión. In: Deitel M, Gagner M, Dixon JB, Himpens J, Madan AK Eds. Handbook of Obesity Surgery. Toronto, Canada: FD-Communications Inc. 2010; pp. $130-6$

[5] Larrad-Jiménez A. Biliopancreatic diversion for the treatment of morbid obesity. Obes Metab 2008; 4:12-21.
[6] Scopinaro N, Marinari GM, Camerini G. Laparoscopic standard biliopancreatic diversion: Technique and preliminary results. Obes Surg 2002;12: 241-4.

[7] Mendieta-Zerón H, Larrad-Jiménez A, Frühbeck G, Da Boit K, Diéguez C. Larrad biliopancreatic diversion in Sprague-Dawley rats. Analysis of weight loss related to food intake. Obes Surg 2009; 19: 484-9.

[8] Larrad Jiménez A, Alvarez MP, Fernández MP, Cano P, Jiménez Ortega V, Esquifino AI. Larrad biliopancreatic diversion. Description of a rat experimental model. Cir Esp 2008; 83:89-92.

[9] Tice JA, Karliner L, Walsh J, Petersen AJ, Feldman MD. Gastric banding or bypass? A systematic review comparing the two most popular bariatric procedures. Am J Med 2008; 121: 885-93.

[10] Williamson RC. Intestinal adaptation: factors that influence morphology. Scand J Gastroenterol Suppl 1982; 74: 21-9.

[11] Sharp JG, Hanson WR, Osborne JW. The relationship between the compensatory response in the stomach and colon and the extent of small bowel resection in the rat. Virchows Arch B Cell Pathol Incl Mol Pathol 1983; 44: 295-304.

[12] O'Brien DP, Nelson LA, Huang FS, Warner BW. Intestinal adaptation: Structure, function, and regulation. Semin Pediatr Surg 2001; 10: 56-64.

[13] Bond JH, Currier BE, Buchwald H, Levitt MD. Colonic conservation of malabsorbed carbohydrate. Gastroenterology 1980; 78: 444-7.

[14] Webb P, Annis JF. Adaptation to overeating in lean and overweight men and women. Hum Nutr Clin Nutr 1983; 37: 117-31.

[15] Masesa PC, Forrester JM. Consequences of partial and subtotal colectomy in the rat. Gut 1977; 18: 37-44

[16] Institute of Laboratory Animal Resources CoLSNRC: Guide for the Care and Use of Laboratory Animals. Washington: National Academy Press 1996.

[17] Ley RE, Bäckhed F, Turnbaugh P, Lozupone CA, Knight RD, Gordon JI. Obesity alters gut microbial ecology. Proc Natl Acad Sci USA 2005; 102: 11070-5

[18] Duncan SH, Lobley GE, Holtrop G. et al. Human colonic microbiota associated with diet, obesity and weight loss. Int J Obes 2008; 32: 1720-4.

[19] Webb P, Annis JF. Adaptation to overeating in lean and overweight men and women. Hum Nutr Clin Nutr 1983; 37: 117-31

[20] Hsiao WWL, Metz C, Singh DP, Roth J. The microbes of the intestine: An introduction to their metabolic and signalin capabilitis. Endocrinol Metab Clin North Am 2008; 37: 857-71

[21] Holt SH, Miller JC, Petocz P, Farmakalidis E. A satiety index of common foods. Eur J Clin Nutr 1995; 49: 675-90

[22] Jayasena CN, Bloom SR. Role of gut hormones in obesity. Endocrinol Metab Clin North Am 2008; 37: 769-87

[23] Lee H, Te C, Koshy S, Teixeira JA, Pi-Sunyer FX, Laferre B. Does ghrelin really matter after bariatric surgery? Surg Obes Relat Dis 2006; 2 : 538-48

Received: October 31, 2012

Revised: November 25, 2012

Accepted: December 01, 2012

(C) Fernández-Mateos et al.; Licensee Bentham Open.

This is an open access article licensed under the terms of the Creative Commons Attribution Non-Commercial License (http://creativecommons.org/licenses/by-nc/3.0/) which permits unrestricted, non-commercial use, distribution and reproduction in any medium, provided the work is properly cited. 